\title{
Development of ex-situ conservation protocol of Ceylon gooseberry [Dovyalis hebecarpa (Gardner) Warb.]
}

\author{
E. M. U. I. Ekanayake and K. M. C. Fernando* \\ Department of Crop Science, Faculty of Agriculture, University of Ruhuna, Mapalana, \\ Kamburupitiya 81100, Sri Lanka. \\ *Email: menaka@crop.ruh.ac.lk
}

Received : 02.02.2021 ; Revised: 30.03.2021 ; Accepted : 03.04.2021

\begin{abstract}
Ex-situ conservation techniques are used effectively to preserve many threatened plant species including Ceylon gooseberry from imminent extinction. The present study was conducted to evaluate an integrated conservation approach which includes seed treatments, seedling establishment and rooting of stem cuttings of Ceylon gooseberry (Dovyalis hebecarpa). Three experiments were set up at the Faculty of Agriculture University of Ruhuna from September 2020 to January 2021. Six seed treatments (seed clipping, cold water soak, hot water treatment, rubbing with fine sand, wood ash, and sandpaper) were used to induce germination of seeds. Germination percentage and germination time were significantly different among treatments. The highest final germination percentage $(53 \%)$ was recorded when seeds were clipped. The best potting mixture for the seedling growth was observed as topsoil: sand: coir-dust: compost, 1:1:1:2 ratio having 60\% seedling survival rate. The commercially available PGR and Aloe vera gel were used to induce rooting in semi-hardwood cuttings. Total root length, number of roots, germination percentage, root and shoot vigour were significantly different among treatments. Ceylon gooseberry seedlings and rooted cuttings could be produced in large scale and establish in the field by adopting the propagation protocol developed in the present study.
\end{abstract}

Keywords: Ceylon gooseberry, Ex-situ conservation, potting mixture, seed treatments, semi-hardwood cuttings

\section{INTRODUCTION}

The rapid loss of biodiversity is one of the most critical environmental challenges faced by the present generation. Ceylon gooseberry (Dovyalis hebecarpa) is also a threatened plant species that belongs to the family Salicaceae. Dovyalis hebecarpa is a perennial shrub growing up to 4-6 meters high with spherical shape berries known as Ceylon gooseberry, or Ketembilla. It is well grown in lower mountain rain forest areas in Sri Lanka. Ceylon gooseberry has far-reaching, unique medicinal qualities and it is a source of anthocyanin and other phytochemicals with great potential to be used for drug preparation (Bochi et al., 2014). The potential health benefits of phenolic compounds present in Ceylon gooseberry are very important for human health and now investigating the antioxidant functions and disease prevention ability of the fruit (Bochi et al., 2015). Ceylon gooseberry fruits contain high antioxidant volume and are acidic fruits. Flavonoids and anthocyanins are the main bioactive compounds responsible for the antioxidant activity of the fruit. In folk medicine, Ceylon gooseberry is often used to medicate infections, eye problems, and diarrhoea. According to Bochi et al. (2015), this is a good source of phytochemicals that could be used for the human to provide defence against free radicals. Moreover, the exocarp of the fruit contains higher levels of secondary plant metabolites than the pulp. Hence, exocarp is a promising source of natural pigments and antioxidants for commercial applications. About $40 \%$ of plants are now in the threat of extinction. Current literature lacks information about the ex-situ conservation methods of this fruit. Therefore the objective of the present study is to develop an integrated approach to ex-situ conservation of Ceylon gooseberry.

\section{MATERIALS AND METHODS}

The present study comprises three experiments. All experiments were carried out at the Department of Crop Science, Faculty of Agriculture, University of Ruhuna, Sri Lanka from September 2020 to January 2021. Plants were grown under controlled conditions in a protected plant house with average temperature of $40^{\circ} \mathrm{C}$ and light intensity of 25,000 lux. 


\section{Experiment 1}

\section{Effect of different seed treatments on germination}

The objective of this experiment was to find out the best seed treatment for rapid and quality germination of Ceylon gooseberry seeds. There were six different mechanical and physical seed treatments, viz., $\mathrm{T}_{1}$-rubbing with fine sand, $\mathrm{T}_{2}$ rubbing with wood ash, $\mathrm{T}_{3}$-rubbing in sandpaper, $\mathrm{T}_{4}$-cold water treatment, $\mathrm{T}_{5}$-hot water soak and $\mathrm{T}_{6}$ seed clipping. A'completely randomized design was used to set up the experiment with five replicates. Fully mature fresh fruits were collected from well-grown gooseberry plants in Matara district belongs to the low country wet zone of Sri Lanka. Seeds collection was done in September 2020. The length and width of fruits and seeds were measured using a vernier caliper and fresh weights were measured using an electronic balance. Seeds were extracted from ripening fruits and altogether 150 seeds were randomly selected for applying treatments. Then 25 seeds were subjected to each treatment with five seeds per replicate. For the first treatment river sand with $0.125-0.25 \mathrm{~mm}$ particle size was used after sieving by a mesh and rub gently for 10 minutes to remove the slimy coat of the seeds and soften the seed coat. As the second treatment timber wood ash was used and it was also gently rubbed for 10 minutes. For the third treatment, sandpaper was used and rubbed the seed sample carefully for 5 minutes. For cold water soak, seeds were soaked 12 hours in cold water while as hot water treatment, seeds were immersed in a $30^{\circ} \mathrm{C}$ water bath for 30 minutes was practiced. Seed clipping was done by damaging the seed coat slightly using a cutter from the pointed end. Then all seeds were wrapped in wet cotton for 2 weeks and during this period germination status was recorded.

Daily germination was recorded for 14 days. Seeds with about $2 \mathrm{~mm}$ radical were considered as germinated seeds. The final germination percentage (FGP; Equation 1), germination rate index (GRI; Equation 2), mean germination time (MGT; Equation 3), and mean daily germination (MDG; Equation 4) were calculated using standard equations (Aravind et al., 2020; Dharmasena \& Arunakumara, 2020) at the end of the experiment.

$$
\begin{aligned}
& F G P=\frac{\text { Number of germinated seeds }}{\text { Total number of seeds sown }} \times 100 \\
& G R I=N 1 / T 1+N 2 / T 2+N 3 / T 3+\ldots .+N n / T n
\end{aligned}
$$

$\mathrm{N} 1, \mathrm{~N} 2, \mathrm{~N} 3, \ldots . ., \mathrm{Nn}=$ number of germinated seeds at a time (days)

$\mathrm{T} 1, \mathrm{~T} 2, \mathrm{~T} 3, \ldots, \mathrm{Tn}=$ number of germinated seeds at a specific time (not the cumulative number).

$$
\operatorname{MGT}=\frac{\sum_{i=1}^{k} N i T i}{\sum_{i=1}^{k} N i}
$$

Where; $\mathrm{Ti}=$ time taken from the beginning to the $\mathrm{i}^{\text {th }}$ observation

$\mathrm{Ni}=$ number of germinated seeds at the $\mathrm{i}^{\text {th }}$ time (not the cumulative number, only take the corresponding number relevant to the $\mathrm{i}^{\text {th }}$ observation)

$\mathrm{k}=$ last time of seeds germination

$$
\mathrm{MDG}=\frac{\text { Final germination percentage }}{\text { Total } \text { mumber of days }}
$$




\section{Experiment 2}

\section{Effect of different potting mixture for growth and development of seedlings}

The objective of this experiment was to select the best potting mixture for seedling growth and survival of Ceylon gooseberry. Germinated seeds of the $1^{\text {st }}$ experiment were sown in nursery trays with compost: sand 1:1 ratio. During the nursery period of three weeks, all the environmental conditions and agronomic practices were equally made to the seedlings to remove any residual effects gained due to various seed treatments. Seedlings which were maintained in nursery trays for three weeks transferred to pots with different potting mixtures $\left(\mathrm{T}_{1}-\right.$ sand: topsoil: coir-dust: compost 1:1:1:1, $\mathrm{T}_{2}-$ sand: topsoil: coir-dust: compost 1:1:1:2, $\mathrm{T}_{3}$ - sand, topsoil, compost $1: 1: 1, \mathrm{~T}_{4}$ - sand: coir-dust: compost 1:1:1). Same sized healthy seedlings were selected and planted according to randomized complete block design with five replicates.Survival percentage and a "vigour" scale for the seedlings were recorded after 4 weeks. As the "vigour" scale, (fully burning -on leaves and wilted nature $=0$, partially burning sign-on leaves and partially wilted $=1$, less than 5 healthy leaves without new buds $=$ 2 , less than 5 leaves with new buds $=3$, more than 5 leaves with new buds and side branches $=4$, more than 5 leaves with new buds, side branches and thorns $=5$ ). Similar visual score was used by Engelbrecht et al. (2007) to measure the wilting nature of seedlings due to drought stress.

\section{Experiment 3}

Effect of commercially available hormone and Aloe vera gel on rooting of semi-hardwood cuttings

The objective of this experiment was to find out the effect of commercially available plant growth regulator (PGR) and the Aloe vera gel on rooting of stem cuttings of Ceylon gooseberry. Semihardwood cuttings of 4-6 inches in length were established in single propagators of size $16^{\prime \prime} \times 5^{\prime \prime}$.
All the cuttings were in same length and same number leaves with half removed leaf blade and having few active buds (Ambagaspitiya et al., 2020). Five different hormone treatments were used $\left(\mathrm{T}_{1}\right.$ - commercial PGR- Rapid root ${ }^{\mathrm{R}}$ containing $0.3 \%$ Indole 3-butyric acid), $\mathrm{T}_{2}$ - dipped in Aloe gel for 2 minutes, $\mathrm{T}_{3}$ - dipped in Aloe gel for 5 minutes, $\mathrm{T}_{4}$ - dipped in Aloe gel for 10 minutes, and $\mathrm{T}_{5}$ - without any treatment (control). In the case of Aloe vera gel, Aloe leaves have been separated from the mother plant two days before extracting gel. The lower portion of the base, the tapering top and the sharp spines of the leaf margin were removed while only the mucilage layer was extracted avoiding vascular bundles, the top rind and the bottom rind (Chandegara and Varshney, 2012). Gel paste was prepared without adding water or any substitute.

General potting mixture of topsoil: sand: coirdust: compost 1:1:1:1/4 was used for filling single propagators and completely randomized design was applied. Five experimental units with 3 replicates were used for each treatment and data were collected after 2 months of initiating single propagators. Survival percentage (Equation 5), the average length of roots $(\mathrm{cm})$, the average number of roots, roots, and shoot "vigour" were evaluated at the end of the trial while lengths of roots were measured manually. "Vigour" scales were introduced to measure the roots and shoot development. As root "vigour" scale, (no callus formation $=0$, callus formation $=1$, callus and roots initiation $=2$, callus and less than five adventitious roots $=3$, callus and more than five adventitious roots $=5$ ) and as shoot "vigour" scale, (brown color dried stem $=0$, moist stem with a green color $=1$, moist stem with green color and less than 3 new buds $=2$, moist stem with green color and more than 3 new buds $=3$, moist green color stem with more than 3 new buds and less than 2 new leaves $=4$, moist green color stem with more than 3 new buds and more than 2 new leaves) were recorded destructively at the end of two months.

$$
\text { Survival percentage }=\frac{\text { Number of rooted } \frac{\text { and }}{\text { or }} \text { call us formed stem cuttings }}{\text { Total number of cuttings used }} \times 100
$$




\section{Statistical analysis}

All the data were analyzed using ANOVA by SAS. Final germination percentage data of experiment 1 and survival percentage data of experiment 3 were subjected to arcsine transformation before analysis. To compare the means of treatments Duncan's Multiple Range Test at $5 \%$ probability was used.

\section{RESULTS AND DISCUSSION}

Table 1 shows the average fresh weight of fruits and seeds of Ceylon gooseberry. The fruit and seed weight varied in the range of 5-7 $\mathrm{g}$ and $55-75 \mathrm{mg}$, respectively. The average size of fruit was $17.17 \pm$ $1.83 \mathrm{~mm}$ in transversal diameter and $16.72 \pm 1.97$ $\mathrm{mm}$ in longitudinal diameter. Similar fruit characteristics evaluation of Elaeagnus latifolia $\mathrm{L}$ was done by Rymbai et al. (2020). Dovyalis fruit color varies during ripening from green to intense brown color and fruits reach their maximum size and biomass accumulation point when the exocarp color is brown while seed removal for propagation should be done when fruits are yellowish-green in hue (Villa et al., 2019).

Table 1: Average length, width and fresh weight of fruits and seeds

\begin{tabular}{lccc}
\hline & $\begin{array}{c}\text { Transversal } \\
\text { diameter } \\
(\mathbf{m m})\end{array}$ & $\begin{array}{c}\text { Longitudinal } \\
\text { diameter } \\
\mathbf{( m m})\end{array}$ & Weight \\
\hline Fruit & $17.17 \pm 1.83$ & $16.72 \pm 1.97$ & $5-7(\mathrm{~g})$ \\
Seed & $3 \pm 1.25$ & $4 \pm 1.55$ & $55-75(\mathrm{mg})$ \\
\hline
\end{tabular}

The highest final germination percentage $(53 \%)$ was recorded in seed clipping treatment $\left(\mathrm{T}_{6}\right)$ which is in significant with fine sand rubbing treatment $\left(T_{1}\right)$ (Fig. 1). The lowest germination percentage was observed from hot water treatment $\left(\mathrm{T}_{5}\right)$ and sandpaper rubbing $\left(\mathrm{T}_{3}\right)$. Duval \& Nesmith (2000) reported enhanced seed germination of watermelon after done clipping and removing the seed coat. It was found that pre-soaking for more than 12 hours does not improve germination. Fathurrahman et al. (2015) investigated that hot water treatment can reduce germination due to embryo damaging when increase the immersing time for Albizia saman plant.

Germination rate index (GRI) defines as the number of seeds germinated within a day and here the highest GRI was recorded from seed clipping $\left(\mathrm{T}_{6}, 0.69\right)$ and rubbing in fine-sand treatments
$\left(\mathrm{T}_{1}, 0.63\right)$ (Fig. 2). These two treatments indicate the highest and fastest germination (Table 3 ). The benefits and weaknesses of GRI have been discussed by Mayer (2000).

The shortest time (5 days) was recorded in seed clipping treatment $\left(\mathrm{T}_{6}\right)$ and fine sand rubbing treatment $\left(T_{1}\right)$ while the longest time is taken for germination by seeds treated with hot water $\left(\mathrm{T}_{5}\right)$ and sandpaper rubbing $\left(\mathrm{T}_{3}\right)(8$ days) (Table 2$)$. In general, the lowest mean of germination time gives the fastest germination. Hence, the highest germination was recorded in $\mathrm{T}_{6}$ while the lowest was recorded from $\mathrm{T}_{5}$. However, $\mathrm{T}_{3}, \mathrm{~T}_{5}$ and $\mathrm{T}_{1}, \mathrm{~T}_{6}$ pairs are not significantly different from others (Fig.1).

The highest mean daily germination (12.80 \%) was recorded from seed clipping $\left(\mathrm{T}_{6}\right)$ while it was not significantly different with the treatment where seeds were rubbed with fine sand $\left(\mathrm{T}_{1}\right)$. The lowest MDG $(2.5 \%)$ was observed from the hot water treatment $\left(T_{5}\right)$ (Table 2). Similarly, the germination measurements are used to make the interpretations and proper decisions during comparisons. Time, rate and, homogeneity can be measured, depicting the dynamics of the germinations. These characteristics are important to predict the success of a species based on the germination within a time frame. Therefore germination is permitting the recruitment of a plant species in a particular ecosystem (Ranal and De Santana, 2006). According to Hartmann et al. (1997), mechanical seed treatments are the best for breaking seed coat dormancy. In the present experiment also gave better result in mechanical and physical seed treatments and the findings was supported from the result of Dahanayake (2015) for 'cardamom seeds'.

In experiment 2 , the highest survival percentage and seedling "vigour" were showed by $\mathrm{T}_{2}$ treatment having sand: topsoil: coir-dust: compost 1:1:1:2 and supporting our results by Khater (2015) who noted the importance of compost for the seedling growth, The lowest survival percentage and seedling vigour were observed from the potting mixture $\left(\mathrm{T}_{3}\right)$ prepared with sand, topsoil, compost 1:1:1 and reason may be due to the lack of coir-dust in the mixture and so compaction can be happened (Figure 3A and 3B). Nazari et al. (2011) has recommended coir-dust as an efficient substitution for potting mixtures. High total pore spaces and water holding capacity of coir-dust may help to grow seedlings in pots and it has been found that growth index shoot and root dry weight of majesty palm increases in coir-dust media (Meerow, 1995). 


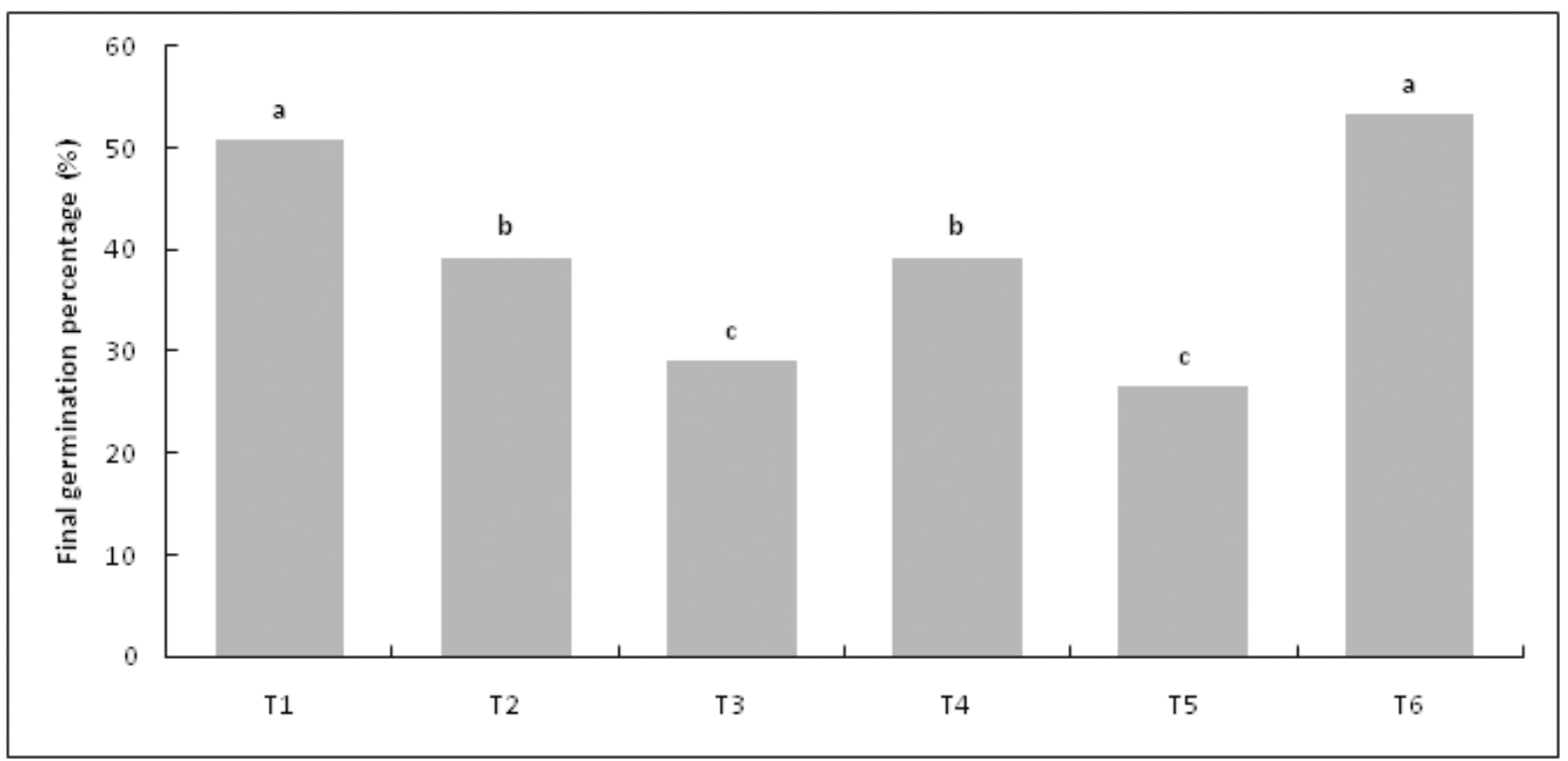

Fig. 1: Effect of different seed treatments on final germination percentage of Ceylon gooseberry seeds. ( $T_{1}$-rubbing with fine sand, $T_{2}$-rubbing with wood $a s h, T_{3}$-rubbing in sandpaper, $T_{4}$-cold water treatment, $T_{5}$-hot water soak and $T_{6}$-seed clipping)

Means with similar letters are not significantly different from each other in $\alpha=0.05$ )

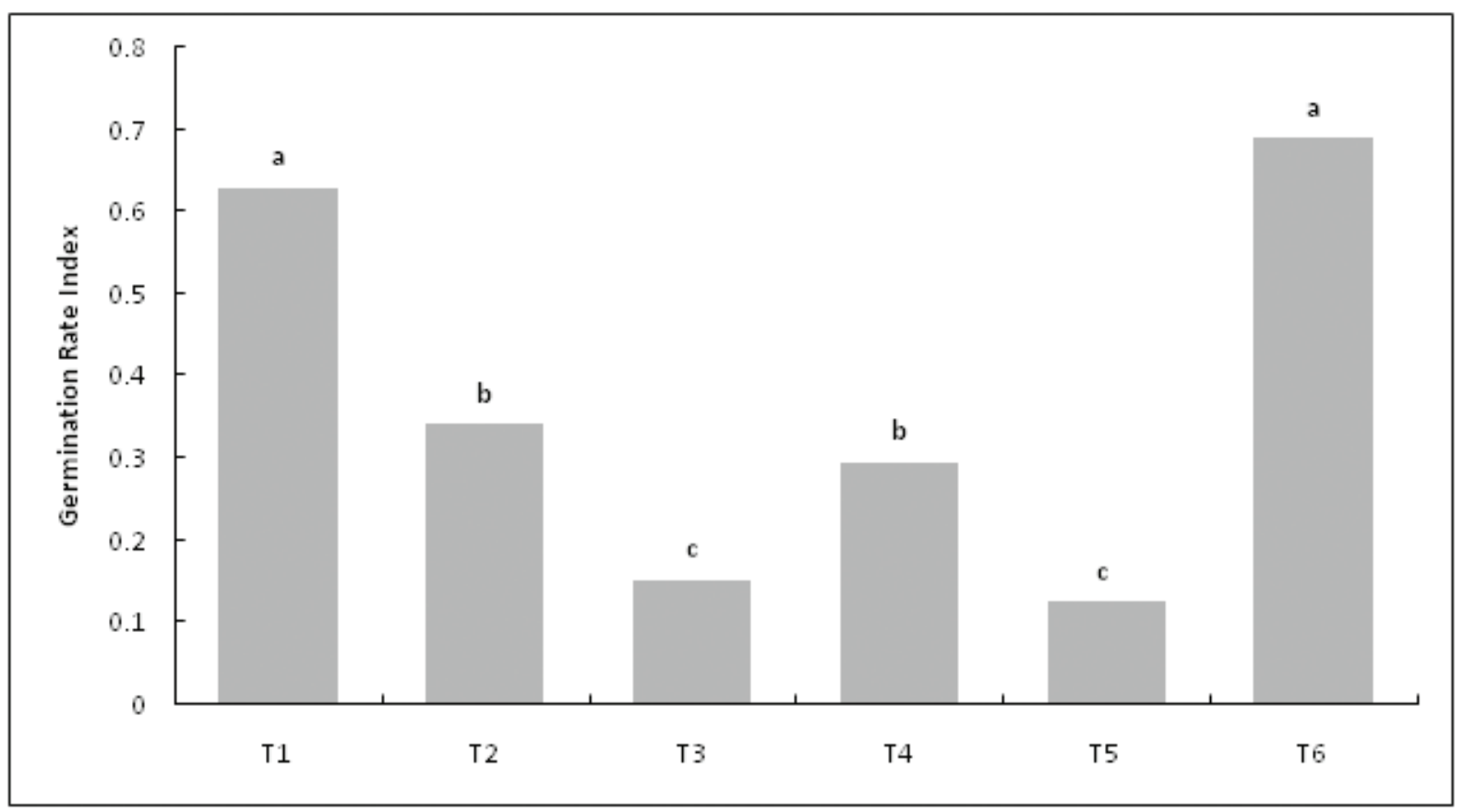

Fig. 2: Effect of different seed treatments on germination rate index of Ceylon gooseberry seeds ( $T_{1}$-rubbing with fine sand, $T_{2}$-rubbing with wood $a s h, T_{3}$-rubbing in sandpaper, $T_{4}$-cold water treatment, $\mathrm{T}_{5}$-hot water soak and $\mathrm{T}_{6}$-seed clipping)

Means with similar letters are not significantly different from each other in $\alpha=0.05$ 
Table 2: Average time for initiating germination, mean germination time and mean daily germination of Ceylon gooseberry seeds

\begin{tabular}{lccc}
\hline Treatments & $\begin{array}{c}\text { Average time for } \\
\text { initiating germination (Days) }\end{array}$ & Mean germination time & Mean daily germination \\
\hline $\mathrm{T}_{1}$ & 5 & $4.796^{\mathrm{d}}$ & $12.0^{\mathrm{a}}$ \\
$\mathrm{T}_{2}$ & 6 & $5.8^{\mathrm{c}}$ & $6.66^{\mathrm{b}}$ \\
$\mathrm{T}_{3}$ & 8 & $7.9^{\mathrm{a}}$ & $3.00^{\mathrm{c}}$ \\
$\mathrm{T}_{4}$ & 7 & $6.6^{\mathrm{b}}$ & $5.71^{\mathrm{b}}$ \\
$\mathrm{T}_{5}$ & 8 & $8.0^{\mathrm{a}}$ & $2.5^{\mathrm{c}}$ \\
$\mathrm{T}_{6}$ & 5 & $4.6^{\mathrm{d}}$ & $12.8^{\mathrm{a}}$ \\
$\mathrm{CV}$ & 21.2 & 3.197 & 12.10 \\
\hline
\end{tabular}

( $T_{1}$-rubbing with fine sand, $T_{2}$-rubbing with wood ash, $T_{3}$-rubbing in sandpaper, $T_{4}$-cold water treatment, $T_{5}$-hot water soak and $T_{6}$-seed clipping).

Means with similar letters are not significantly different from each other in $\alpha=0.05$ )

Table 3: Average number of roots, the average length of roots, root vigour, and shoot vigour of semi-hardwood cuttings under different treatments

\begin{tabular}{lcccc}
\hline Treatments & $\begin{array}{c}\text { Average number } \\
\text { of roots }\end{array}$ & $\begin{array}{c}\text { Average length } \\
\text { of roots }\end{array}$ & Root vigour & Shoot vigour \\
\hline T1 & $3.75^{\mathrm{a}}$ & $6.22^{\mathrm{a}}$ & $4.50^{\mathrm{a}}$ & $4.25^{\mathrm{a}}$ \\
$\mathrm{T} 2$ & $1.33^{\mathrm{c}}$ & $1.20^{\mathrm{c}}$ & $1.33^{\mathrm{c}}$ & $1.50^{\mathrm{c}}$ \\
$\mathrm{T} 3$ & $2.44^{\mathrm{b}}$ & $4.01^{\mathrm{b}}$ & $2.66^{\mathrm{b}}$ & $2.33^{\mathrm{b}}$ \\
$\mathrm{T} 4$ & $3.69^{\mathrm{a}}$ & $5.97^{\mathrm{a}}$ & $4.55^{\mathrm{a}}$ & $4.50^{\mathrm{a}}$ \\
$\mathrm{T} 5$ & $1.17^{\mathrm{c}}$ & $0.59^{\mathrm{d}}$ & $1.16^{\mathrm{c}}$ & $1.16^{\mathrm{c}}$ \\
CV & 9.35 & 8.53 & 10.10 & 12.25 \\
\hline
\end{tabular}

( $T_{1}$ - commercial PGR- Rapid root ${ }^{\circledR}$ containing $0.3 \%$ Indole 3-butyric acid, $T_{2}$ - dipped in Aloe gel for 2 minutes, $T_{3}$ - dipped in Aloe gel for 5 minutes, $T_{4}$ - dipped in Aloe gel for 10 minutes, and $T_{5}$ without any treatment -control)

Means with similar letters are not significantly different from each other in $\alpha=0.05$ )

In experiment 3 , the commercial IBA hormone treatment $\left(\mathrm{T}_{1}\right)$ and dipping in Aloe vera gel for 10 minutes $\left(\mathrm{T}_{4}\right)$ were not significantly different from each other for the rooting percentage of semihardwood cuttings of Ceylon gooseberry which were giving the highest rooting percentage (Figure 4 ). Control treatment without any hormone application $\left(\mathrm{T}_{5}\right)$ was showed the lowest rooting and our findings are fine-tune with the (Almeida et al., 2004) who used IBA for air layering of Ceylon gooseberry for getting better success.

The highest average number of roots, length of roots, root, and shoot "vigour" were observed from commercial PGR applied cuttings ( $\left.\mathrm{T}_{1}\right)$ and cuttings were dipped in Aloe vera gel for 10 minutes $\left(\mathrm{T}_{4}\right)$ (Table 3). Increasing in dipping times of stem cuttings in Alo vera gel may caused higher accumulation of plant metabolites in the cuttings that increased their rooting numbers and length. According to Mirihagalla and Fernando (2020), root length, the number of roots and root "vigour" of the semi-hardwood cuttings of Citrus aurantifolia treated commercial PRG (Rapid $\operatorname{root} \AA, 0.3 \%$ Indole 3-butyric acid; IBA) and dipped cuttings ends in fresh Aloe vera gel for two and five minutes were not significantly different. Shidiki et al. (2019) showed that IBA, Aleo vera gel, and coconut water showed comparable influence on root initiation while number of primary roots was highest in Aloe vera gel treatment. They were dipped in 2 minutes in each treatment. Similarly, Uddin et al. (2020) showed that the highest root development and survival percentages were recorded from IBA 


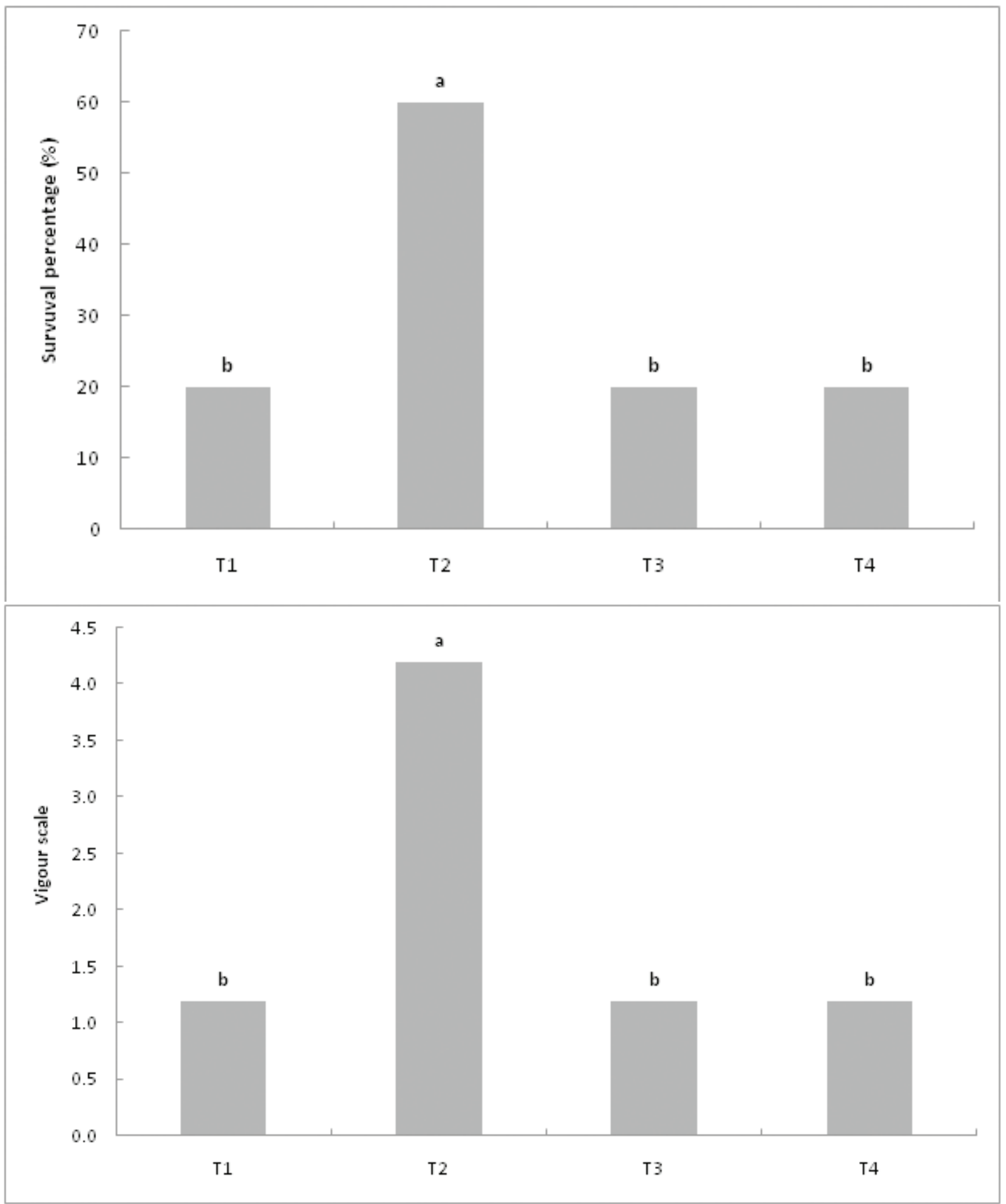

Fig. 3: Effect of different potting mixtures on (A) survival percentage of seedlings and (B) "vigour" of seedlings

( $T_{1}$ - sand 1: topsoil 1: coir-dust 1: compost 1, $T_{2}$ - sand 1: topsoil 1: coir-dust 1: compost 2, $T_{3}$ - sand 1, topsoil 1, compost $1, T_{4}$ - sand 1: coir-dust 1: compost 1 )

Means with similar letters are not significantly different from each other in $\alpha=0.05$ ) 


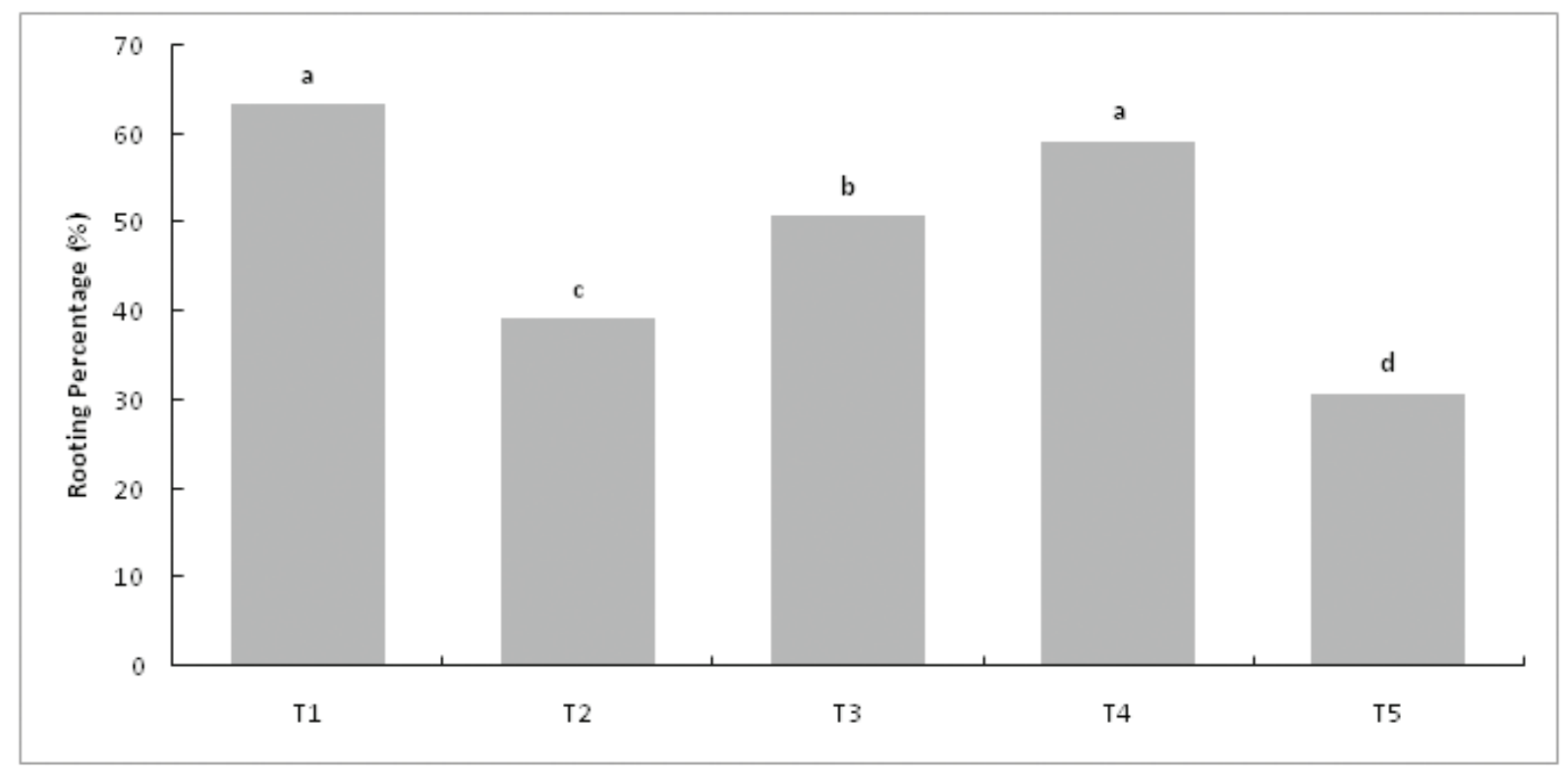

Fig. 4: Effect of different treatments on rooting percentage of semi-hardwood cuttings of Ceylon gooseberry two months after establishment

$\left(\mathrm{T}_{1}\right.$ - commercial PGR- Rapid root ${ }^{\circledR}$ containing $0.3 \%$ Indole 3-butyric acid, $\mathrm{T}_{2}$ - dipped in Aloe gel for 2 minutes, $\mathrm{T}_{3}$ - dipped in Aloe gel for 5 minutes, $\mathrm{T}_{4}$ - dipped in Aloe gel for 10 minutes, and $\mathrm{T}_{5}$ - without any treatment -control).

Means with similar letters are not significantly different from each other in $\alpha=0.05$ )
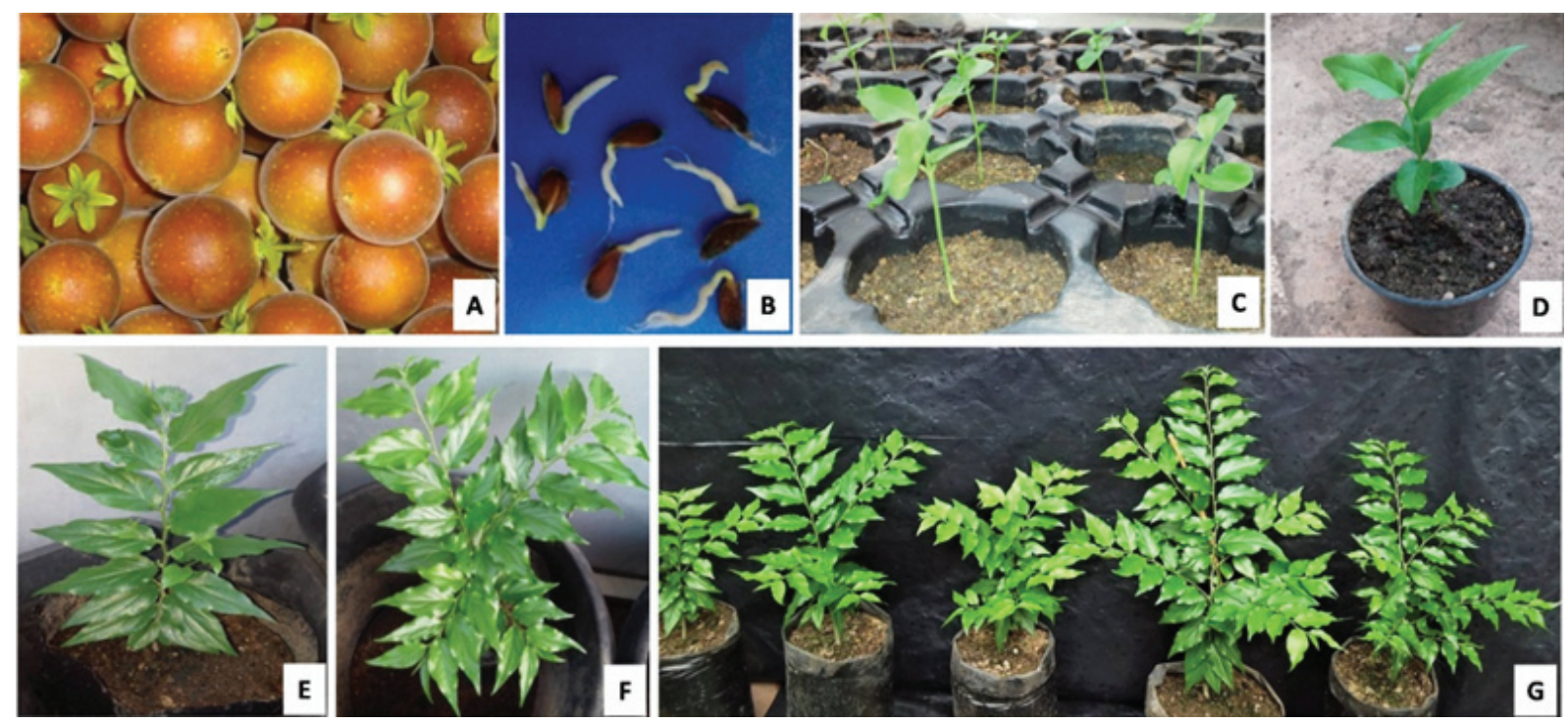

Plate 1: (A) Ripen fruits of Ceylon gooseberry (B) germinated seeds (C) seedling tray nursery (D) transferred seedling to a pot (E) two months old seedling (F) three months old seedling (G) seedlings are ready to be transplanted in the field

which results were closed to natural Aloe vera gel treatment. The lowest rooting and "vigour" were showed in the control treatment without any hormone or PGRs (Table 3). Aloe vera gel contains mainly polysaccharides and many other compounds like carboxypeptidase, minerals, glucose, vitamins, amino acids, auxins, and gibberellins (Shariff Moghaddasi and Verma, 2011). The use of cuttings for propagation is a fast method and it allows bringing favorable mother characteristics having an agronomic interest (Pourghorban et al., 2019). 


\section{CONCLUSION}

Conservation of Ceylon gooseberry (Dovyalis hebecarpa) species is essential by using propagating techniques since it is gradually disappearing from the natural habitats. According to the results of three experiments, it can be concluded that the physical and mechanical seed treatments can be used to enhance seed germination while potting mixture prepared by sand: topsoil: coir-dust: compost 1:1:1:2 could be used for seedling growth. Commercially available PGRs like Rapid root ${ }^{\circledR}(0.3 \%$ Indole 3 -butyric acid $)$ and cutting ends dipped in Aloe vera gel for 10 minutes could be recommended for inducing rooting of semi-hardwood cuttings. Furthermore, for rooting of Ceylon gooseberry, commercial PGRs can be effectively replaced by Aloe vera gel. The commercial scale production of Ceylon gooseberry seedlings and rooted cuttings can be achieved by following the propagation protocol developed in the present study.

\section{REFERENCES :}

Almeida, E. J. de, Jesus, N. de, Ganga, R. M. D., Benassi, A. C., Scaloppi Junior, E. J., and Martins, A. B. G. 2004. Propagação de Dovyalis sp. peloprocesso de mergulhiaaérea. RevistaBrasileira de Fruticultura, 26(3): 511-514.

Ambagaspitiya, W.U.L., Nawarathna, S.L., Yapa, P.I. and Krishnarajah, S.A. 2020. Propagation of Bauhinia kockiana Korth through stem cuttings as affected by maturity stage of cuttings and different biofertilizers. International Journal of Minor Fruits, Medicinal and Aromatic Plants, 6(1):43-49.

Aravind, J., Vimala Devi, S., Radhamani, J., Jacob, S. R. and Srinivasan, K. 2020. The germination metrics package: A brief Introduction. 46. ftp://ftp.onet.pl/pub/mirrors/ CRAN/web/packages/germinationmetrics/ vignettes/Introduction.pdf

Bochi, V. C., Barcia, M. T., Rodrigues, D. and Godoy, H. T. 2015. Biochemical Characterization of Dovyalis hebecarpa Fruits: A source of snthocyanins with high antioxidant capacity. Journal of Food Science, 80(10): C2127-C2133.
Bochi, V. C., Barcia, M. T., Rodrigues, D., Speroni, C. S., Giusti, M. M. and Godoy, H. T. 2014. Polyphenol extraction optimisation from Ceylon gooseberry (Dovyalis hebecarpa) pulp. Food Chemistry, 164: 347-354.

Chandegara, V. and Varshney, A.K. 2012. Aloe vera: Development of gel extraction process for Aloe vera leaves. LAP LAMBERT Academic Publishing.

Dahanayake, N. 2015. Application of seed treatments to increase germinability of cardamom (Elettaria cardamomum) seeds under in vitro conditions. Sabaragamuwa University Journal. 14(2): 101. https:// doi.org/10.4038/suslj.v14i2.7698

Dharmasena, K. P. S. S. and Arunakumara, K. K. I. U. 2020. Effect of Plant Growth Regulators on Seed Germination in Walla Patta (Gyrinops walla). Sri Lankan Journal of Agriculture and Ecosystems, 2(2): 56-69.

Duval, J. R. and Nesmith, D. S. 2000. Treatment with hydrogen peroxide and seed coat removal or clipping improve germination of "Genesis" triploid watermelon. Hort. Science, 35(1): 85-86.

Engelbrecht, B.M., Tyree, M.T. and Kursar, T.A., 2007. Visual assessment of wilting as a measure of leaf water potential and seedling drought survival. Journal of Tropical Ecology, 23(4): 497-500.

Fathurrahman, Said, M. N. M., Ahmad, W. J. W., Doni, F. and Radziah, C. C. 2015. Germination and seedling response of rain tree plants (Albizia saman Jacq. Merr) to seed priming using hot water. Ecology, Environment and Conservation, 21(3): 11831187.

Hartmann H. T., Kester D. E., Davies F. Jr. and Geneve R. L. 1997. Plant Propagation Principles and Practices. Sixth Edition. New Jersey, Prentice Hall.

Khater, E. S. G. 2015. Some physical and chemical properties of compost. International Journal of Waste Resources, $\mathbf{0 5}(01)$. https://doi.org/ 10.4172/2252-5211.1000172

Mayer, R. F. B. and D. G. 2000. A critical analysis of Maguire's germination rate index. Journal of Seed Technology, 10 (2): 101-110. 
Meerow, A. W. 1995. Growth of two tropical foliage plants using coir dust as a container medium amendment. Hort. Technology, 5(3): 237-239.

Mirihagalla, M. K. P. N. and Fernando, K. M. C. 2020. Effect of Aloe vera gel for Inducing Rooting of Stem Cuttings and Air layering of Plants. Journal of Dry Zone Agriculture, 6(1):13-26.

Nazari, F., Farahmand, F., Khosh-Khui, M. and Salehi, H. 2011. Effects of Different Pot Mixtures on Vegetative, Reproductive and Physiological Characteristics of Iranian Hyacinth (Hyacinthus orientalis L. cv. Sonbol-eIrani). International Journal of Agricultural and Food Science, 1(2): 34-38.

Pourghorban, M., Khaghani, S., Azadi, P., Mirzakhani, A. and Changizi, M. 2019. Propagation of rosa hybrida L. Cv. dolce vita by stenting and stem cutting methods in response to different concentrations of IBA. Advances in Horticultural Science, 33(1): 105-111.

Ranal, M. A. and De Santana, D. G. 2006. How and why to measure the germination process? Revista Brasileira de Botanica, 29(1): 1-11.

Rymbai, H., Deshmukh, N.A., Talang, H.D., Assumi, S.R., Devi, M.B., Mawlein, J. and
Jha, A.K., 2020. Evaluation of fruit characteristics of Elaeagnus latifolia L. in the North Eastern hill region, India. International Journal of Minor Fruits, Medicinal and Aromatic Plants, 6(1): 38-42.

Shariff Moghaddasi. M. and Verma, S. K. 2011. Aloe vera their chemicals composition and applications/ : A review. International Journal of Biological and Medical Research, 2(1): 466-471.

Shidiki, A.A., Ambebe, T.F. and Mendi, A.G. 2019. A comparative evaluation of Indole-3-Butyric Acid and plant extracts as potential rooting enhancers in cuttings of Vitex diversifolia and Cordia milleneii. International Journal of Forest, Animal and Fisheries Research, 3(4):154-159.

Uddin, A.J., Rakibuzzaman, M., Raisa, I., Maliha, M. and Husna, M.A. 2020. Impact of natural substances and synthetic hormone on grapevine cutting. Journal of Bioscience and Agriculture Research, 25(01): 2069-2074.

Villa, F., Fernandes da Silva, D., Rotili, M. C. C., Herzog, N. F. M. and Malavasi, M. M. 2019. Seed physiological quality and harvest point of dovyalis fruits. Pesquisa Agropecuária Tropical. V.49. e54520.https://doi.org/ 10.1590/1983-40632019v4954520 